\title{
GIS-Mapping of Soil Available Plant Nutrients (Potentiality, Gradient, Anisotropy)
}

\author{
Abd El-Nabi Mohamed Abd El-Hady¹, Emad Fawzy Abdelaty1*, Abdubaset Egrira Salama2,3 \\ ${ }^{1}$ Department of Natural Resources \& Agricultural Engineering, Faculty of Agriculture, Damanhour University, Damanhour, Egypt \\ ${ }^{2}$ Faculty of Agriculture, Bani Waleed University, Bani Waleed, Libya \\ ${ }^{3}$ Damanhour University, Damanhour, Egypt \\ Email: hadyhady200@damanhour.edu.eg, *emad.fawzy@damanhour.edu.eg
}

How to cite this paper: Abd El-Hady, A.M., Abdelaty, E.F. and Salama, A.E. (2018) GIS-Mapping of Soil Available Plant Nutrients (Potentiality, Gradient, Anisotropy). Open Journal of Soil Science, 8, 315-329.

https://doi.org/10.4236/ojss.2018.812023

Received: October 28, 2018

Accepted: December 4, 2018

Published: December 7, 2018

Copyright $\odot 2018$ by authors and Scientific Research Publishing Inc. This work is licensed under the Creative Commons Attribution International License (CC BY 4.0).

http://creativecommons.org/licenses/by/4.0/

\section{Open Access}

\begin{abstract}
The research was elaborated in Kafr El-Dawar area (Egypt northern region) to study the availability of the soil plant nutrients. The research introduced three parameters to comprehensively and carefully describe the availability of the soil plant nutrients: potentiality, gradient and anisotropy. Potentiality defines the categories of soil ability to supply plant nutrients; meanwhile gradient expresses the increasing rate of the availability of the soil plant nutrients. The gradient anisotropy refers to the directions or orientation of the increasing rate of the availability of the soil plant nutrients. The introduced parameters enabled to spatially study the availability of the soil plant nutrients. Analytical data, of soil available phosphorus (P), indicated that $\mathrm{P}$ ranged from $0.2 \mathrm{ppm}$ to $11.4 \mathrm{ppm}$ to locate all studied soil samples into the low class of the soil nutritional $\mathrm{P}$ ability. This was not the case of available potassium $(\mathrm{K})$, where the soil samples were distributed into three available $\mathrm{K}$ soil categories: medium, high, and very high. GIS map of soil $\mathrm{P}$ nutritional potentiality for plant (potato), displayed the soil studied area in one category, as low P soil nutritional potentiality to coincide with the analytical data classification. Contrary, the $\mathrm{K}$ map classified the soil studied area into three categories of soil $\mathrm{K}$ nutritional potentiality: medium, high and excessive. This obviously referred that the individual determination of soil $\mathrm{K}$ nutritional potentiality is misleading for interpretation of soil tests because it does care of the spatial distribution of soil available K. Nearly, all soil samples had high available micronutrients that they were located in the high category in both classification of analytical data and GIS maps. GIS gradient maps of the soil available plant nutrients referred that the soil plant nutrients, exception of $\mathrm{K}$, had two gradients: non increasing-slight increasing and build up. Gradient of soil available potassium was classified into four classes: non increasing-slight increasing, build up, moderately increasing and hike. Regardless potassium case, the non increasing-slight increasing gradient class dominated the others. GIS
\end{abstract}


maps of anisotropy soil availability of macronutrients ( $\mathrm{P}$ and $\mathrm{K}$ ) generally showed that their gradients mainly increased in two directions: north and south. The incasing directions of soil availability of micronutrients coincided with that of the macronutrients.

\section{Keywords}

GIS Mapping, Available Soil Plant Nutrients, Potentiality, Gradient, Anisotropy

\section{Introduction}

The study of soil plant micronutrient availability is worthwhile because it enables to: 1) detect and manage micronutrient deficiencies, and 2) determine plant requirements fertilizers [1]. Micronutrient deficiencies can be detected by visual symptoms on crops and by testing soils and plant tissues [2]. Soil availability of plant nutrients is low, leading to deficiency symptoms and crops decreasing [3]. When availability is low, different fertilizers application rates are normally recommended for highly responsive and medium responsive [4]. Soil plant micronutrient availability is mainly affected by soil $\mathrm{pH}$. The desirable soil $\mathrm{pH}$ range for optimum plant growth varies among crops. Generally, soil pH 6.0 - 7.5 is acceptable for most plants as most nutrients become available in this $\mathrm{pH}$ range. Soil $\mathrm{pH}$ can be determined by mixing soil sample with water and then measuring the resulting aqueous solution [5] [6].

A variety of approaches have been used to survey and map the geographic distribution of soil micronutrient content and availability at scales ranging from global to sites within single production fields. Soil micronutrient maps covering large areas improve our understanding of the nature and extent of micronutrient problems, and aid in determining their relationships with climate, soil properties, and soil genetic characteristics. Highly detailed maps of soil micronutrient content and availability in individual fields are being developed for site-specific precision agriculture. Soil micronutrient maps have fostered discovery of relationships between soil micronutrient content and availability. Advances including the global positioning system (GPS), geographic information systems (GIS), inductively coupled plasma (ICP) spectrometry, geostatistics, and precision agriculture facilitate soil micronutrient mapping and provide quantitative support for decision and policy making to improve agricultural approaches to balanced micronutrient nutrition [7]. Soil micronutrient maps showing the spatial distribution were prepared in Arc Info GIS. The maps of Fe, Mn, $\mathrm{Zn}, \mathrm{Cu}$ and B nutrients clearly indicated the deficiency of nutrients constrained in soil for crop production. Based upon the coefficient of determination between micronutrients and soil properties, a positive correlation was observed between organic carbon and $\mathrm{Mn}, \mathrm{Cu}$ and $\mathrm{Zn}$. The $\mathrm{CaCO}_{3}$ content in the soil showed negative and significant correlation with available $\mathrm{Fe}$ and $\mathrm{Mn}[8]$. 


\section{Materials and Methods}

The study was elaborated through four stages. The first stage was consecrated to build-up spatial database by processing of topographic maps: 1) collection, digitizing and mosaicking of the topographic maps 2) mosaicking clipping the topographic maps excerpt the studied area, by using the software of geographic information system (ArcGIS 9.3). The second stage was consecrated to the field work to collect the samples of surface soil samples $(0-40 \mathrm{~cm})$. Laboratory work represented the third which included that determination of heavy metal soil content and chemical characterization of water samples. Final stage was the synthesis of laboratory data to write the thesis (Figure 1).

\subsection{Building-Up Spatial Database (Topographic Maps Processing)}

Building-up Spatial Database was built through the processes of maps collection, digitizing, mosaicking and Clipping. Nine 1:50,000-scaled topographic maps [9] were digitized by Arc-GIS 9.3 software [10]. The coordinate was converted from the geographic coordinates (Lat.-Long.) system to Universal Transverse Mercator (UTM) coordinates system (Easting-Northing). The topographic map sheets, covering the surrounding region, were merged together in one map to compose mosaic map. The mosaic was clipped to extract the study area that has the coordinates $(222,000 \mathrm{E}$ and 3,450,000 N) (the upper left corner) (Figure 2).

\subsection{Sampling and Analysis of Surface Soil Samples}

\subsubsection{Soil Sampling}

Twenty-five soil samples surface $(0-40 \mathrm{~cm})$ were collected to represent the root zone of the studied area (Kafr El-Dawar, Egypt northern region), at 24-12-2015 (Figure 2). The samples were aired air dried and crushed pass through $2 \mathrm{~mm}$ sieve to elaborate the different analysis. Soil sampling was carried out using the systematic nested gridding soil sampling design of $5^{\star} 5$ samples that covered an

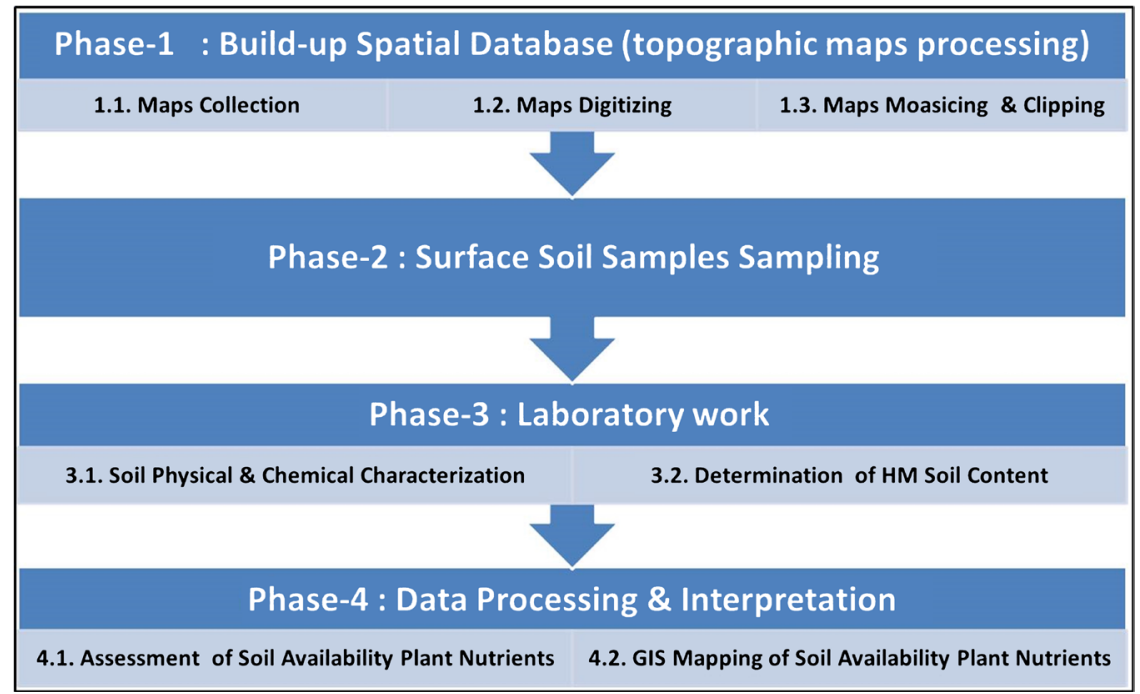

Figure 1. Summarized research plan. 


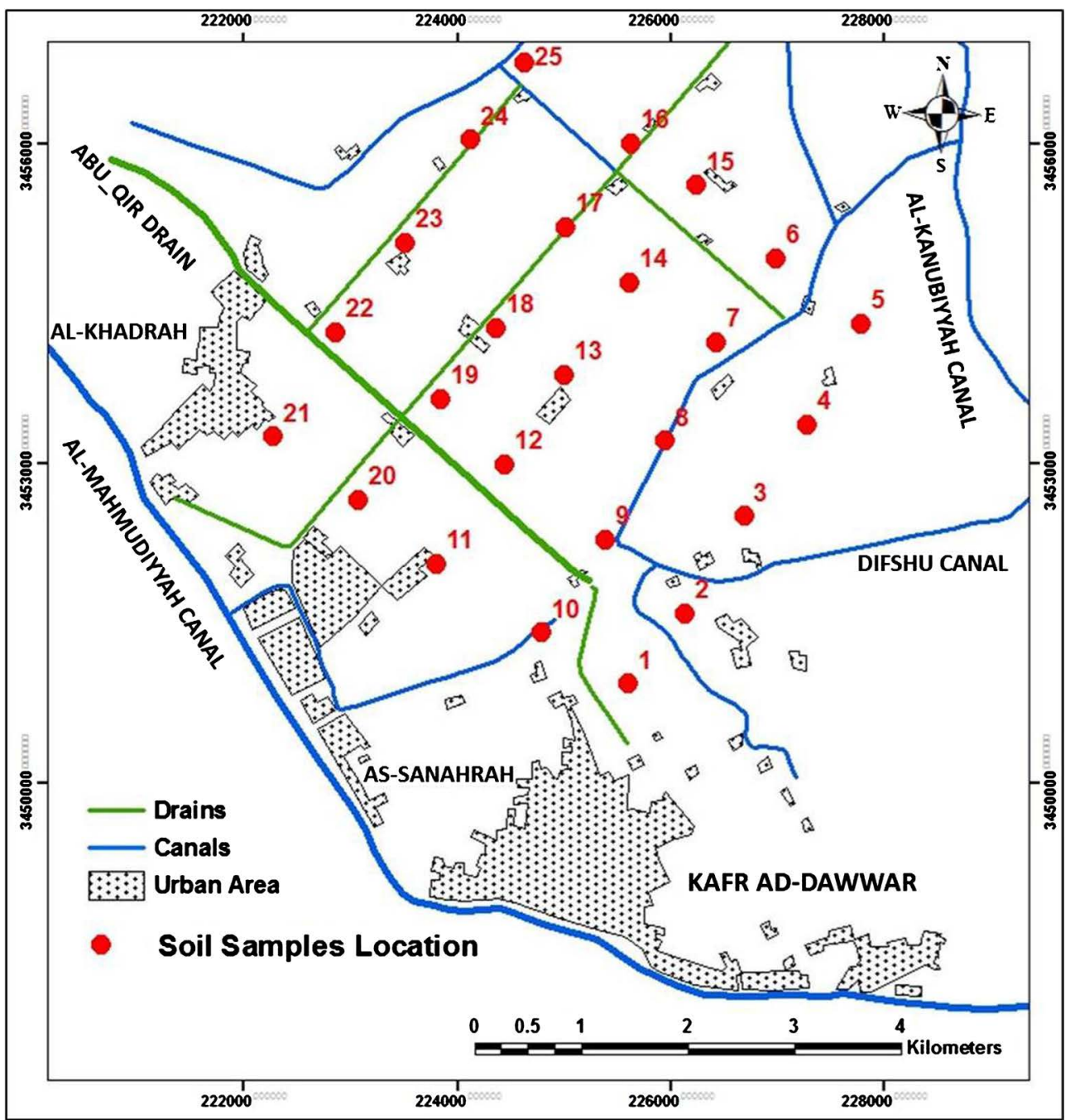

Figure 2. Studied area and soil samples locations (Kafr El-Dawar, Egypt northern region).

area (Figure 2). Soil samples locations were determined by GPS NAVA 600 (accuracy of $\pm 5 \mathrm{~m}$ ).

\subsubsection{Soils Physical and Chemical Characterization}

- Soil Physical Analysis. Texture was determined using sieves and Hydrometer method [11].

- Soil Chemical Analysis: Salinity was measured at in the soil paste extract and $\mathrm{pH}$ of 1:2.5 soil suspension by EC meter and $\mathrm{pH}$ [12], Sodium Absorption Ration (SAR) was calculated from $\mathrm{Ca}, \mathrm{Mg}$ and $\mathrm{Na}$ soluble concentrations, soil organic matter content (OM\%) was determined by Walkely \& Black method [12] and $\mathrm{CaCO}_{3} \%$ was determined using the pressure calcimeter method [12].

1) Determination of Soils Content of Available Nutrients (K, P, Fe, Zn, $\mathrm{Mn}, \mathrm{Cu}$ ):

Soil available phosphorous, potassium and micro-nutrients (iron, manganese, zinc and copper) was extracted by [13] [14], potassium was measured by Flame 
Photometer [12], phosphorous was measured by spectrophotometer and micronutrients were measured by Atomic Absorption.

\section{2) GIS-Mapping of Soil Availability of Plant Nutrients:}

Analytical data of soil available plant nutrients were processed by ARC-GIS 9.3 [10] to map soil nutritional ability. Maps of gradient and anisotropy of soil availability of plant nutrients were derived from GIS-map of soil nutritional ability.

\section{Results and Discussion}

\subsection{Physical and Chemical of the Soil Surface Samples}

Twenty five soils surface samples $(0-40 \mathrm{~cm})$ were taken from the clipped agricultural area. Soils locations were determined by their UTM coordinates (Table 1 and Figure 2). The results of particle size distribution classified the collected soil samples into two textural classes (Table 2).

- Clay loam (samples no. 1, 6, 7, 8, 9, 14, 15, 16, 17, 18, 19, 19, 20, 21, 22, 23, 24).

○ Sandy clay loam (samples no. 2, 3, 4, 5, 11, 12, 13, 25).

The high $\mathrm{pH}$ values obviously indicated that the soils are alkaline ones. All samples lied out of the desirable soil pH 6.0 - 7.5, where most plants as most nutrients become available in this $\mathrm{pH}$ range. The maximal $\mathrm{pH}$ value was 8.8 to represent extremely alkaline soil (sample: 5 ). $\mathrm{pH}$, as criterion, classified the soil samples into two classes (Table 3 ).

- Alkaline soils that had $\mathrm{pH}$ values 7.92 and 7.84 for samples 9 and 21, respectively.

- Extremely alkaline soils that had $\mathrm{pH}$ values $\geq 8$ (samples: $1,2,3,4,5,6,7,8$, $10,11,12,13,14,15,16,17,18,19,21,22,23,24,25)$.

Table 1. UTM coordinates of soil samples.

\begin{tabular}{cccccc}
\hline \multirow{2}{*}{ No } & \multicolumn{2}{c}{ Soil Samples Coordinates (UTM) } & & \multicolumn{2}{c}{ Soil Samples Coordinates } \\
\cline { 2 - 3 } \cline { 5 - 6 } & Easting & Northing & & Easting & Northing \\
\hline 1 & 225,603 & $3,450,932$ & 14 & 225,615 & $3,454,696$ \\
2 & 226,136 & $3,451,593$ & 15 & 226,247 & $3,455,607$ \\
3 & 226,693 & $3,452,504$ & 16 & 225,634 & $3,455,997$ \\
4 & 227,288 & $3,453,359$ & 17 & 225,021 & $3,455,217$ \\
5 & 227,789 & $3,454,306$ & 18 & 224,370 & $3,454,269$ \\
6 & 226,990 & $3,454,919$ & 19 & 223,850 & $3,453,600$ \\
7 & 226,433 & $3,454,139$ & 20 & 223,070 & $3,452,653$ \\
8 & 225,950 & $3,453,210$ & 21 & 222,271 & $3,453,247$ \\
9 & 225,392 & $3,452,281$ & 22 & 222,865 & $3,454,232$ \\
10 & 224,798 & $3,451,408$ & 23 & 223,516 & $3,455,068$ \\
11 & 223,813 & $3,452,058$ & 24 & 224,129 & $3,456,034$ \\
12 & 224,445 & $3,452,987$ & 25 & 224,630 & $3,456,759$ \\
13 & 225,002 & $3,453,833$ & & & \\
\hline
\end{tabular}


Table 2. Soil textural classes.

\begin{tabular}{|c|c|c|c|c|c|c|c|c|c|}
\hline \multirow{2}{*}{ Sample No. } & \multicolumn{3}{|c|}{ Particle Size Distribution (\%) } & \multirow{2}{*}{ Textural Class } & \multirow{2}{*}{ Sample No. } & \multicolumn{3}{|c|}{ Particle Size Distribution (\%) } & \multirow{2}{*}{ Textural Class } \\
\hline & Sand & Silt & Clay & & & Sand & Silt & Clay & \\
\hline 1 & 51.8 & 26.2 & 22.0 & Sandy Clay Loam & 14 & 42.9 & 28.6 & 28.5 & Clay Loam \\
\hline 2 & 42.9 & 28.6 & 28.5 & Clay Loam & 15 & 44.2 & 27.3 & 28.5 & Clay Loam \\
\hline 3 & 44.2 & 26.6 & 29.2 & Clay Loam & 16 & 51.8 & 26.2 & 22.0 & Sandy Clay Loam \\
\hline 4 & 43.5 & 29.5 & 27.0 & Clay Loam & 17 & 50.8 & 26.4 & 22.8 & Sandy Clay Loam \\
\hline 5 & 41.6 & 30.4 & 28.0 & Clay Loam & 18 & 42.9 & 30.1 & 27.0 & Clay Loam \\
\hline 6 & 51.8 & 26.2 & 22.0 & Sandy Clay Loam & 19 & 41.6 & 28.3 & 30.1 & Clay Loam \\
\hline 7 & 42.9 & 28.6 & 28.5 & Clay Loam & 20 & 44.2 & 26.3 & 29.5 & Clay Loam \\
\hline 8 & 42.3 & 28.8 & 28.9 & Clay Loam & 21 & 43.5 & 29.5 & 27.0 & Clay Loam \\
\hline 9 & 42.9 & 27.6 & 29.5 & Clay Loam & 22 & 41.6 & 30.8 & 27.6 & Clay Loam \\
\hline 10 & 51.8 & 25.4 & 22.8 & Sandy Clay Loam & 23 & 42.9 & 27.6 & 29.5 & Clay Loam \\
\hline 11 & 50.8 & 26.7 & 22.5 & Sandy Clay Loam & 24 & 44.2 & 28.8 & 27.0 & Clay Loam \\
\hline 12 & 51.8 & 26.5 & 21.7 & Sandy Clay Loam & 25 & 53.7 & 23.4 & 22.9 & Sandy Clay Loam \\
\hline 13 & 51.8 & 26.2 & 22.0 & Sandy Clay Loam & & & & & \\
\hline
\end{tabular}

This extreme alkalinity is mainly due to the soil high calcium carbonates that ranged from $7.5 \%$ (sample: 1 ) to $28.6 \%$ (sample: 6), (Table 3). The table showed that the samples were distributed into three salinity classes:

- Nonsaline soils: (samples from 1 to 11 , then 14 , from 16 to 20 and from 23 25).

- Slightly saline soils: (samples 12,13,15 and 15).

- Saline soils: (sample: 21).

In addition, the table indicated that the majority of soil samples had low SAR values. Some samples were moderately sodic $(22,23)$. Other samples had high SAR to be sodic ones $(13,15)$. Generally, the soil low organic matter content that ranged from $0.53 \%$ (samples no. 13,21 ) to $5.3 \%$ (sample: 1 ).

\subsection{GIS-Mapping of Availability of Soil Plant Nutrients}

\subsubsection{GIS-Mapping of Soil Nutritional Potentiality for Plants}

The available soil plant nutrients were determined to assess the soil nutritional ability. Soil nutritional ability was classified into four categories; low, medium, high and very high (for macronutrients; $\mathrm{P}$ and $\mathrm{K}$ ), (Table 4) and three categories; low, adequate and high (for micronutrients; $\mathrm{Fe}, \mathrm{Mn}, \mathrm{Zn}$ and $\mathrm{Cu}$ ) [15] (Table 5). The guidelines of the table distrusted the soil samples into their categorical classification (Table 6). The table indicated the soil available phosphorus ranged from $0.2 \mathrm{ppm}$ (sample no. 17), $11.4 \mathrm{ppm}$ (sample no. 1). These values led to group all studied soil samples into the class of low soil nutritional $\mathrm{P}$ ability. This was not the case of available potassium $(\mathrm{K})$, where the soil samples were distributed into three available $\mathrm{K}$ soil categories; medium (samples: 6, 8, 10 and 23), 
Table 3. Chemical characteristics of soil surface samples.

\begin{tabular}{|c|c|c|c|c|c|c|c|c|c|c|c|}
\hline \multirow{2}{*}{ Sam. No } & \multirow{2}{*}{$\mathrm{pH}$} & \multirow{2}{*}{$\mathrm{EC} \mathrm{dS} / \mathrm{m}$} & \multicolumn{6}{|c|}{ Soluble Ions (meq/L) } & \multirow{2}{*}{ SAR } & \multirow{2}{*}{$\mathrm{CaCO}_{3}(\%)$} & \multirow{2}{*}{$\mathrm{OM}(\%)$} \\
\hline & & & $\mathrm{Ca}^{+2}$ & $\mathrm{Mg}^{+2}$ & $\mathrm{Na}^{+}$ & $\mathrm{K}^{+}$ & $\mathrm{Cl}^{-}$ & $\mathrm{SO}_{4}^{2-}$ & & & \\
\hline 1 & 8.63 & 1.24 & 7.45 & 3.00 & 2.90 & 0.30 & 4.60 & 4.00 & 1.30 & 7.50 & 5.30 \\
\hline 2 & 8.46 & 0.72 & 2.00 & 1.00 & 4.00 & 0.10 & 3.20 & 1.90 & 3.30 & 20.20 & 1.47 \\
\hline 3 & 8.29 & 2.91 & 15.00 & 12.50 & 4.00 & 0.40 & 6.00 & 19.90 & 1.10 & 17.10 & 1.54 \\
\hline 4 & 8.52 & 2.04 & 10.00 & 7.50 & 6.40 & 0.40 & 16.00 & 3.30 & 2.20 & 12.90 & 2.25 \\
\hline 5 & 8.80 & 1.15 & 4.00 & 3.60 & 3.70 & 0.10 & 5.40 & 2.00 & 1.90 & 16.80 & 1.68 \\
\hline 6 & 8.41 & 3.06 & 25.00 & 7.00 & 4.00 & 0.20 & 7.50 & 22.70 & 1.0 & 28.60 & 1.40 \\
\hline 7 & 8.39 & 1.58 & 5.00 & 4.80 & 5.30 & 0.10 & 8.80 & 3.40 & 2.40 & 21.40 & 1.79 \\
\hline 8 & 8.55 & 1.10 & 3.80 & 3.00 & 4.20 & 0.10 & 5.20 & 2.90 & 2.30 & 18.30 & 1.75 \\
\hline 9 & 7.92 & 3.55 & 19.42 & 9.10 & 14.50 & 0.20 & 16.00 & 22.70 & 3.80 & 16.80 & 2.14 \\
\hline 10 & 8.40 & 1.04 & 5.13 & 1.90 & 4.90 & 0.10 & 4.00 & 3.60 & 2.60 & 13.20 & 1.44 \\
\hline 11 & 8.18 & 3.28 & 19.58 & 8.40 & 10.70 & 0.20 & 22.50 & 10.40 & 2.90 & 19.20 & 2.95 \\
\hline 12 & 8.28 & 4.17 & 20.00 & 9.50 & 16.20 & 2.30 & 30.00 & 10.00 & 4.20 & 21.60 & 3.33 \\
\hline 13 & 8.28 & 6.29 & 16.50 & 7.50 & 49.40 & 0.50 & 60.00 & 7.90 & 14.30 & 12.60 & 0.53 \\
\hline 14 & 8.67 & 0.78 & 3.00 & 1.80 & 2.80 & 0.10 & 2.80 & 2.10 & 1.80 & 22.00 & 1.40 \\
\hline 15 & 8.28 & 7.31 & 20.00 & 25.50 & 38.60 & 0.40 & 67.50 & 9.50 & 8.10 & 16.50 & 1.75 \\
\hline 16 & 8.66 & 1.54 & 4.40 & 3.60 & 7.80 & 0.20 & 9.80 & 2.20 & 3.90 & 15.60 & 1.58 \\
\hline 17 & 8.50 & 1.49 & 5.00 & 4.00 & 6.80 & 0.10 & 8.00 & 4.90 & 3.20 & 12.30 & 0.77 \\
\hline 18 & 8.22 & 1.62 & 5.80 & 4.60 & 7.70 & 0.20 & 10.00 & 5.90 & 3.40 & 12.00 & 0.39 \\
\hline 19 & 8.09 & 2.06 & 9.00 & 4.50 & 10.00 & 0.70 & 12.50 & 6.70 & 3.80 & 19.50 & 3.96 \\
\hline 20 & 8.00 & 1.00 & 4.80 & 2.40 & 4.30 & 0.20 & 4.80 & 2.90 & 2.30 & 18.00 & 1.86 \\
\hline 21 & 7.84 & 9.55 & 40.00 & 10.00 & 50.10 & 1.10 & 85.00 & 11.20 & 10.00 & 12.60 & 0.53 \\
\hline 22 & 8.42 & 4.62 & 20.00 & 10.00 & 22.90 & 0.40 & 30.00 & 15.30 & 5.90 & 15.60 & 2.03 \\
\hline 23 & 8.46 & 2.49 & 8.00 & 6.00 & 13.80 & 0.30 & 20.00 & 3.10 & 5.20 & 13.50 & 1.16 \\
\hline 24 & 8.66 & 0.99 & 3.63 & 1.80 & 5.80 & 0.40 & 7.20 & 1.60 & 3.50 & 15.00 & 2.10 \\
\hline 25 & 8.42 & 2.64 & 12.00 & 7.00 & 11.50 & 0.20 & 20.00 & 5.70 & 3.70 & 15.30 & 2.74 \\
\hline $\mathrm{CO}_{3}^{2-}=$ & $00(\mathrm{~m}$ & & & & & & & & & & \\
\hline
\end{tabular}

high (samples: 2, 5, 7, 9, 11, from 14 to 17, 20, 24 and 25) and very high (samples no: $1,4,12,13,19,21$ and 22 ).

GIS data processing output the maps of soil nutritional potentiality for plant (potato). Figure 3 displayed the soil studied area in one category, as low P soil nutritional potentiality to coincide with the classification of Table 6. Contrary, classified the soil studied area into three categories of soil $\mathrm{K}$ nutritional potentiality; medium (74.5 ha, 2.4\%), high (1699.4 ha, 54.5\%) and excessive (1345.2 ha, $43.1 \%)$. This referred that the individual determination of soil $\mathrm{K}$ nutritional potentiality is misleading for interpretation of soil tests because it does care of 
Table 4. Categorical classification of soils available phosphorus (P) and potassium (K) (for potato) [15].

\begin{tabular}{ccccc}
\hline No. & Available $(\mathrm{P}) \mathrm{ppm}$ & $(\mathrm{P})$ Soil Categories & Available (K) ppm & K Soil Categories \\
\hline 1 & $<20$ & Low & $0-60$ & Low \\
2 & $20-40$ & Medium & $61-120$ & Medium \\
3 & $40-100$ & High & $121-180$ & High \\
4 & $>100$ & Very High (Excessive) & $>180$ & Very High (Excessive) \\
\hline
\end{tabular}

Table 5. Guidelines of categorical classification, for potatoes, of soil available micronutrients [15].

\begin{tabular}{ccccc}
\hline Element & Iron $(\mathrm{Fe})$ & Manganese $(\mathrm{Mn})$ & Zinc $(\mathrm{Zn})$ & $\mathrm{Copper}(\mathrm{Cu})$ \\
\hline Extraction Method & DTPA & DTPA & DTPA & DTPA \\
Low & $<2.5$ & $<0.6$ & $<1.0$ & $<0.6$ \\
Adequate & $2.5-5.0$ & $0.6-2.0$ & $>1.5$ & $0.60-2.0$ \\
High & $>5.0$ & $>2.0$ & $>1.5$ & $>2.0$ \\
\hline
\end{tabular}

Table 6. Categories of soil nutritional ability for plant nutrients.

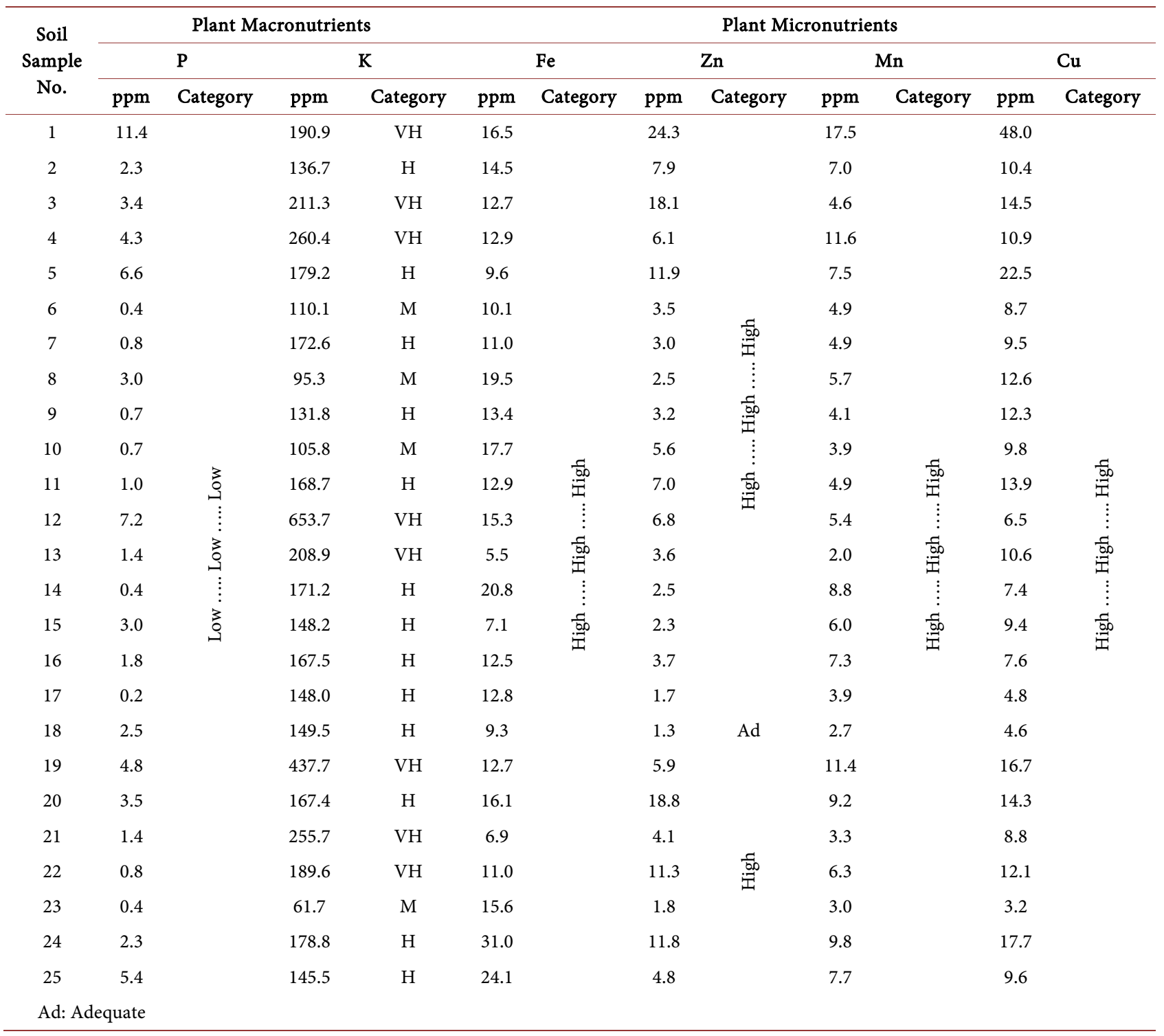


the spatial distribution of soil available K. Evidently, the classification of soil plant nutritional potentiality can be based on analytical data and GIS maps of georferenced of analytical data. This analytical data-classification is misleading, especially in high variation case, for interpretation of soil tests. The GIS maps-classification of soil plant nutritional potentiality is more accurate because it does care of the spatial distribution of soil plant nutrients available $\mathrm{K}$.

All soil samples had high available micronutrients that they were located in the high category (Table 6). This with exception of soil sample (18) that had an adequate level of available $\mathrm{Zn}$. Results of $\mathrm{Zn}$ soil nutritional potentiality in Figure 3 were classified the studied area into two categories; adequate (2.6 ha, $0.1 \%)$ and high (3116.5 ha, $99.9 \%$ ). The soil high content of available micronutrients is mainly due to the act that they are irrigated with high riched-micronutrients irrigation [16].

\subsubsection{Gradient of Soil Availability of Plant Nutrients}

GIS gradient maps of the available soil plant nutrients were derived from GIS-maps of soil nutritional potentiality for plant (Figure 4). The maps were based on four gradient classes (Table 7). Hence, Gradient of soil availability of plant nutrients is mainly affected by soil slope the assigned values of gradient classes are derivative from soil slope classes [17].

GIS gradient maps of the soil available plant nutrients guided to study their rate spatial changes (Figure 4). The figure generally referred that the soil plant nutrients, exception of $\mathrm{K}$, had two gradients; non increasing-slight increasing and build up. Gradient of soil available potassium was classified into four classes; non increasing-slight increasing, build up, moderately increasing and hike. Regardless potassium case, the non increasing-slight increasing gradient class dominated the others. This class occupied large area; $\mathrm{P}$ (3112.3 ha, 99.8\%), Fe (2973.9 ha, 95.3\%), Mn (3090.5 ha, 99.1\%), Zn (2985.2 ha, 95.7\%) and $\mathrm{Cu}$ (3051.7 ha, 97.8\%) (Table 8).

Table 7. Derivative classes of gradient of soil availability of plant nutrients.

\begin{tabular}{cccc}
\hline Class & Gradient (\%) & Class & Gradient (\%) \\
\hline Non increasing-slight increasing & $0.0-1.0$ & Moderately increasing & $5-15$ \\
Build up & $1-5$ & Hike & more 30 \\
\hline
\end{tabular}

Table 8. Classes gradient of soil plant micronutrients availability.

Plant Micronutrients

\begin{tabular}{|c|c|c|c|c|c|c|c|c|c|c|c|c|}
\hline \multirow{4}{*}{ Anisotropy of Soil Availability } & & & & & & & & & & & & \\
\hline & \multicolumn{2}{|c|}{$\mathbf{P}$} & \multicolumn{2}{|c|}{$\mathbf{K}$} & \multicolumn{2}{|c|}{$\mathrm{Fe}$} & \multicolumn{2}{|c|}{ Mn } & \multicolumn{2}{|c|}{$\mathrm{Zn}$} & \multicolumn{2}{|c|}{$\mathrm{Cu}$} \\
\hline & \multicolumn{2}{|c|}{ Area } & \multicolumn{2}{|c|}{ Area } & \multicolumn{2}{|c|}{ Area } & \multicolumn{2}{|c|}{ Area } & \multicolumn{2}{|c|}{ Area } & \multicolumn{2}{|c|}{ Area } \\
\hline & ha & $\%$ & ha & $\%$ & ha & $\%$ & ha & $\%$ & ha & $\%$ & ha & $\%$ \\
\hline Non increasing-slight increasing $(0.0 \%-1 \%)$ & 3112.3 & 99.8 & 500.2 & 16.0 & 2973.9 & 95.3 & 3090.5 & 99.1 & 2985.2 & 95.7 & 3051.2 & 97.8 \\
\hline Build up $(1 \%-5 \%)$ & 6.8 & 0.2 & 1532.4 & 49.1 & 145.2 & 4.7 & 28.6 & 0.9 & 133.9 & 4.3 & 67.9 & 2.2 \\
\hline Moderately increasing (5\% - 15\%) & 0.0 & 0.0 & 828.2 & 26.6 & 0.0 & 0.0 & 0.0 & 0.0 & 0.0 & 0.0 & 0.0 & 0.0 \\
\hline Hike (15\%) & 0.0 & 0.0 & 258.3 & 8.3 & 0.0 & 0.0 & 0.0 & 0.0 & 0.0 & 0.0 & 0.0 & 0.0 \\
\hline
\end{tabular}




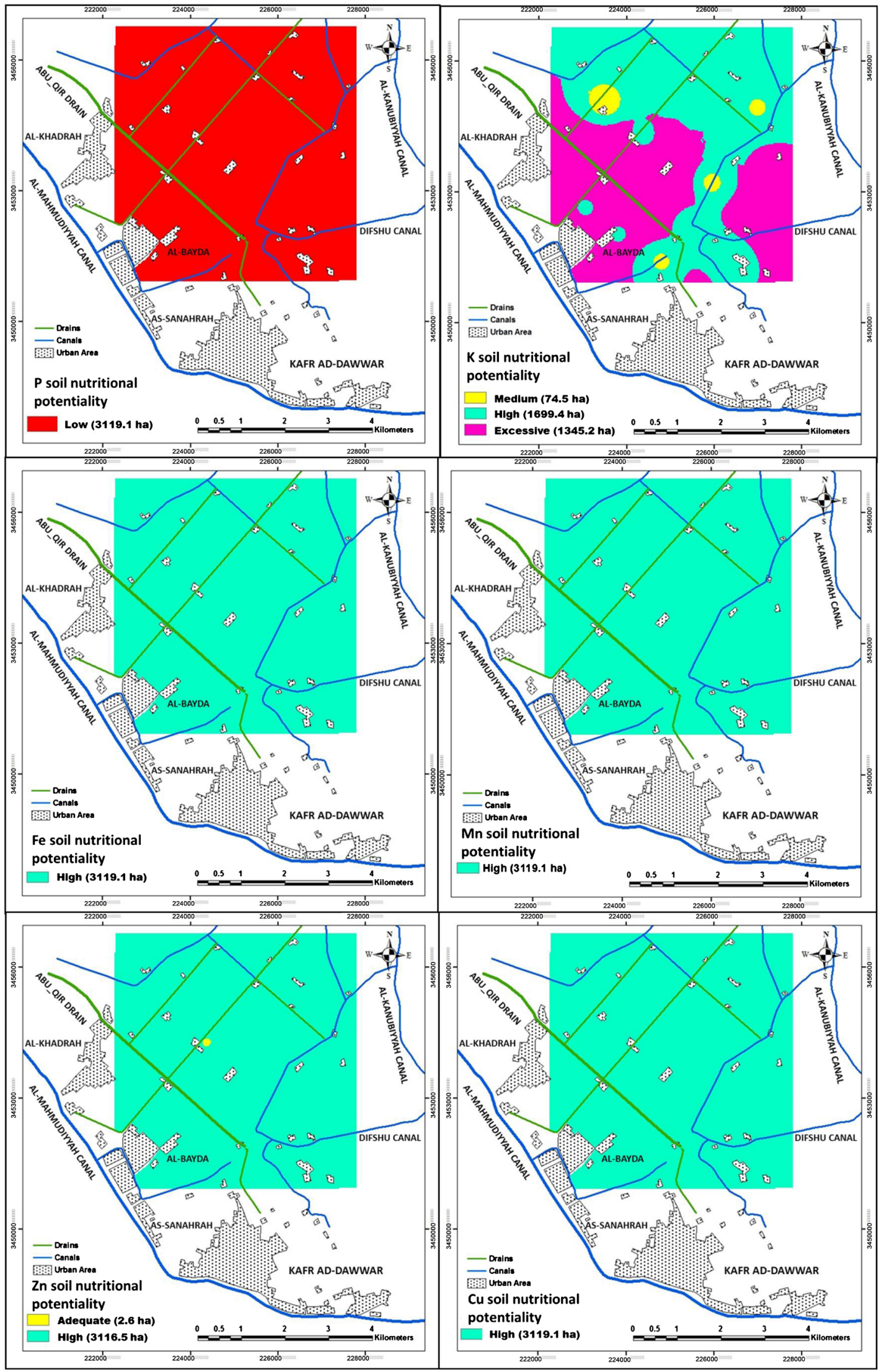

Figure 3. GIS-maps of soil nutritional potentiality for plant (potato). 


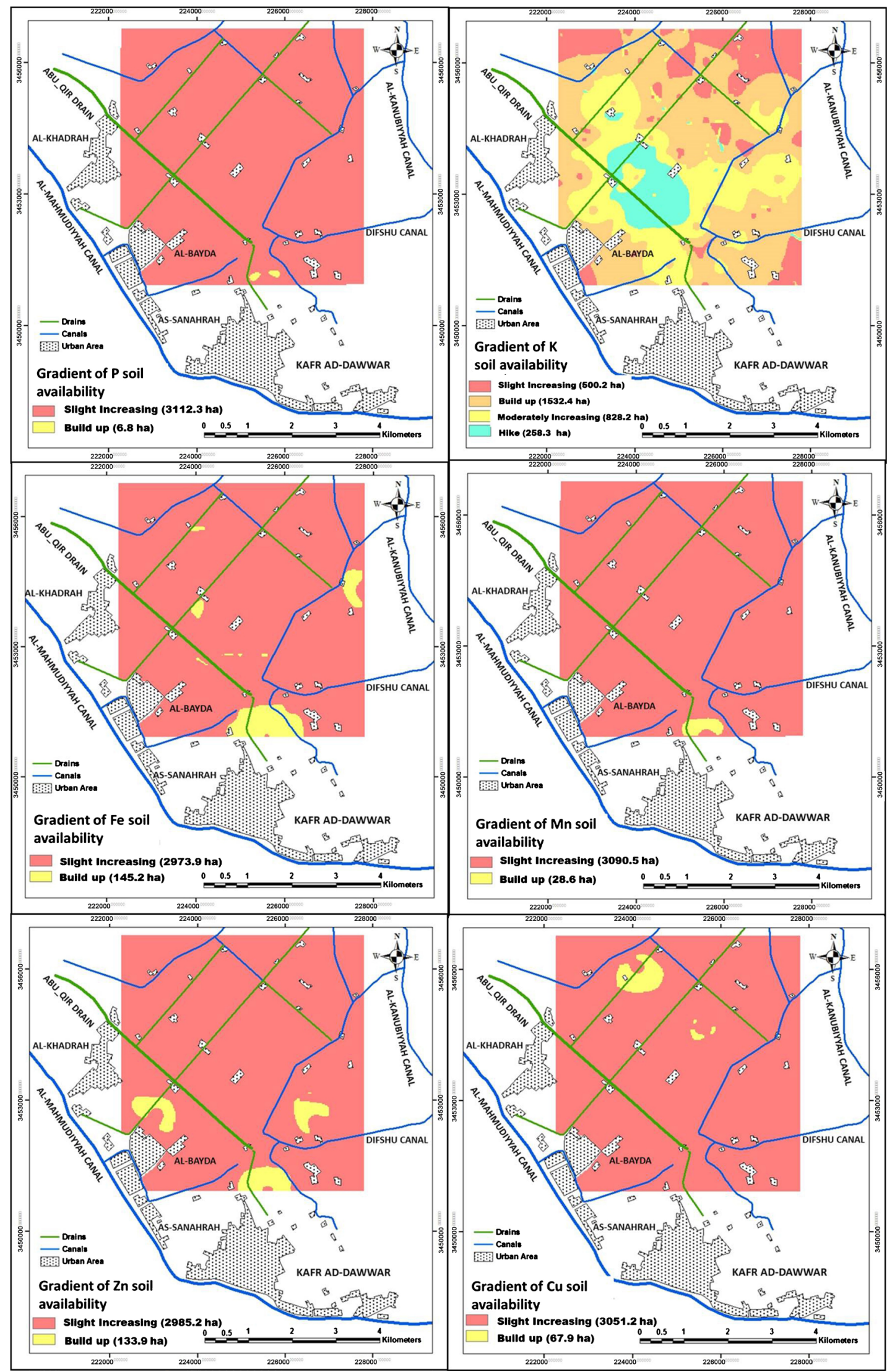

Figure 4. Gradient of soil availability of plant nutrients. 


\subsubsection{Gradient Anisotropy of Soil Availability of Plant Nutrients}

Anisotropy or orientation of soil availability gradient of plant nutrients is so similar to slope aspects that is derived from digital elevation model (DEM). The research introduced a unique and main difference by the substitution of elevation data by soil content of the available plant nutrients to output the digital soil availability model of plant nutrients (DAM). GIS technique enabled to derive Anisotropy or orientation of soil availability gradient of plant nutrients from (DAM) (Figure 5). GIS maps of anisotropy soil availability of macronutrients (P and $\mathrm{K}$ ) (Figure 5) generally showed that their gradients mainly increased in two directions; north (1235.7 ha, 39.6\% for $\mathrm{P}$, and 1215.2 ha, 39.0\% for $\mathrm{K}$ ), and south (1320.1 ha, $42.3 \%$ for P, and 1182.5 ha, $37.9 \%$ for K) (Table 9).

The incasing directions of soil availability of micronutrients coincided with that of the macronutrients ( $\mathrm{P}$ and $\mathrm{K}$ ); north (1320.1 ha, 42.3\% for Fe, 1229.1 ha, 39.4\% for $\mathrm{Mn}, 1363.5 \mathrm{ha}, 43.7 \%$ for $\mathrm{Zn}$ and 1587.1 ha, $50.9 \%$, for $\mathrm{Cu}$ ), and south (1258.5 ha, $40.3 \%$ for Fe, 1203.2 ha, 38.6\% for Mn, 898.5 ha, 28.8\% for $\mathrm{Zn}$ and $762.2 \mathrm{ha}, 24.4 \%$, for $\mathrm{Cu}$ ) (Figure 5 and Table 9). This anisotropy or orientation pattern of direction north-south is due to the direction of application irrigation water that was highly riched-nutrients [16].

\section{Conclusions}

The guidelines of soil typical nutrients concentration must be considered to accurately determine the soil plant nutrient availability, and especially micronutrient. The accurate determination of soil availability of plant nutrient guides to better calculation of crops fertilizers requirements that certainly are the road map of crop maximal crops production.

The comprehensive and accurate description of soil nutrients availability is built on three parameters: potentiality, gradient and gradient anisotropy. Soil nutritional potentiality defines the categories of soil ability to supply plant nutrients. The gradient points out to the increasing rate of nutritional potentiality. For gradient anisotropy, it describes the directions or orientation pattern increasing nutritional potentiality rate. Hence GIS technique enables to display the

Table 9. Gradient anisotropy of soil availability of plant micronutrients.

Plant Micronutrients

\begin{tabular}{|c|c|c|c|c|c|c|c|c|c|c|c|c|}
\hline \multirow{3}{*}{$\begin{array}{l}\text { Anisotropy of } \\
\text { Soil Availability }\end{array}$} & \multicolumn{2}{|c|}{$\mathbf{P}$} & \multicolumn{2}{|c|}{$\mathrm{K}$} & \multicolumn{2}{|c|}{$\mathrm{Fe}$} & \multicolumn{2}{|c|}{ Mn } & \multicolumn{2}{|c|}{$\mathrm{Zn}$} & \multicolumn{2}{|c|}{$\mathrm{Cu}$} \\
\hline & \multicolumn{2}{|c|}{ Area } & \multicolumn{2}{|c|}{ Area } & \multicolumn{2}{|c|}{ Area } & \multicolumn{2}{|c|}{ Area } & \multicolumn{2}{|c|}{ Area } & \multicolumn{2}{|c|}{ Area } \\
\hline & ha & $\%$ & ha & $\%$ & ha & $\%$ & ha & $\%$ & ha & $\%$ & ha & $\%$ \\
\hline North & 1235.7 & 39.6 & 1215.2 & 39.0 & 1320.1 & 42.3 & 1229.1 & 39.4 & 1363.5 & 43.7 & 1587.1 & 50.9 \\
\hline East & 183.2 & 5.9 & 417.1 & 13.4 & 241.4 & 7.7 & 329.6 & 10.6 & 426.9 & 13.7 & 199.3 & 6.4 \\
\hline South & 1320.1 & 42.3 & 1182.5 & 37.9 & 1258.5 & 40.3 & 1203.2 & 38.6 & 898.5 & 28.8 & 762.2 & 24.4 \\
\hline West & 380.1 & 12.2 & 304.3 & 9.8 & 299.1 & 9.6 & 357.2 & 11.5 & 430.2 & 13.8 & 570.5 & 18.3 \\
\hline
\end{tabular}




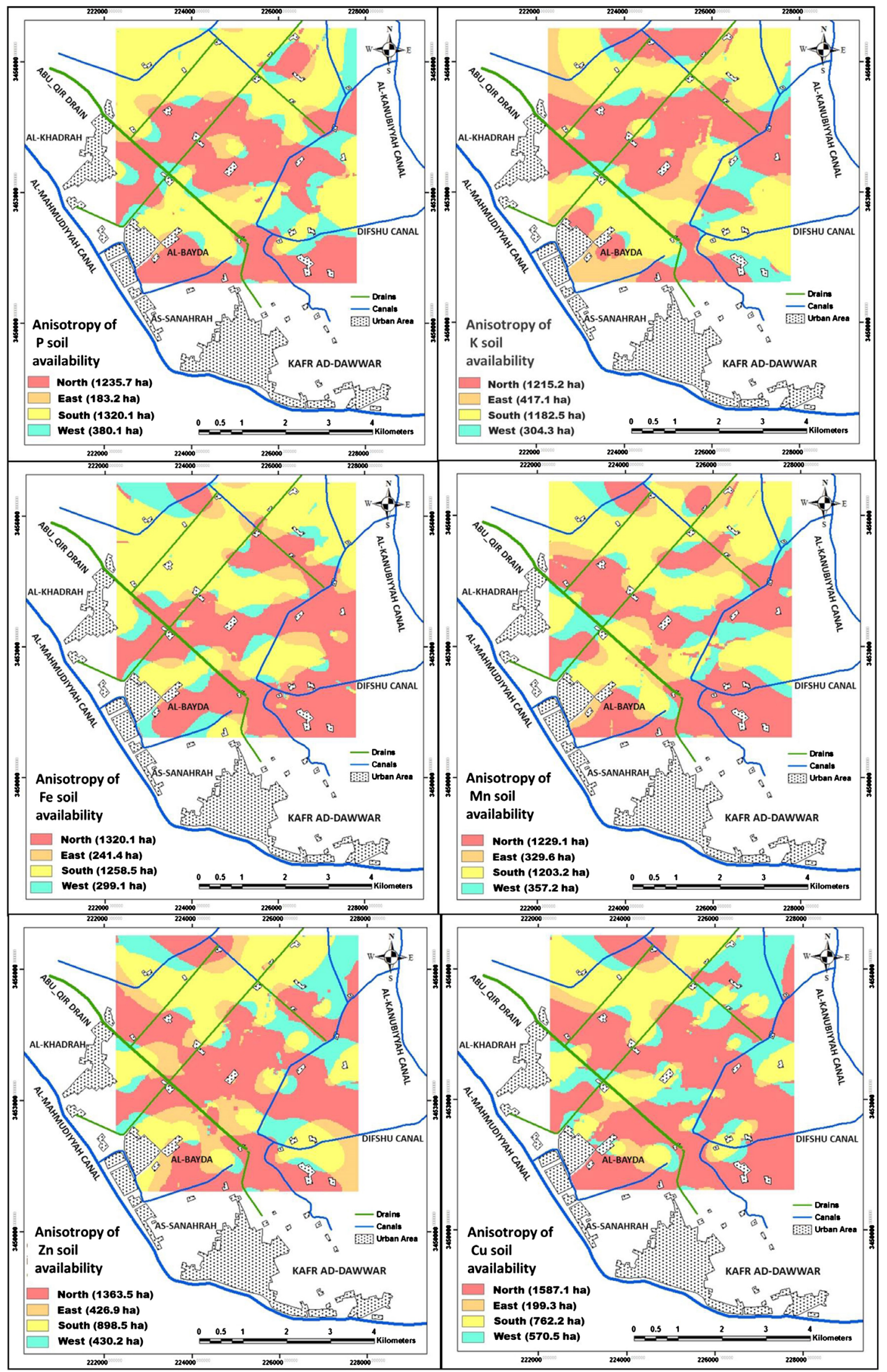

Figure 5. Anisotropy of nutrients soil availability for plant (potato). 
spatial distribution and variation, of a soil character, is considered as unique and accurate procedure to study the parameters of soil availability of plant nutrients.

The classification of soil plant nutritional potentiality can be based on analytical data and GIS maps of georferenced analytical data. This analytical data-classification is misleading, especially in high variation case, for interpretation of soil tests. The GIS maps-classification of soil plant nutritional potentiality is more accurate because it does care of the spatial distribution of soil plant nutrients available $\mathrm{K}$.

\section{Conflicts of Interest}

The authors declare no conflicts of interest regarding the publication of this paper.

\section{References}

[1] Hartz, T.K. (2007) Soil Testing for Nutrient Availability Procedures and Interpretation for California Vegetable Crop Production. Department of Plant Sciences, UC Davis, University of California, USA. (In Egypt) https://vric.ucdavis.edu/pdf/fertilization_Soiltestingfornutrientavailability2007.pdf

[2] Bautzen, S. (2018) Micronutrients for Crop Production. (In Egypt) https://www.pioneer.com/home/site/us/agronomy/micronutrients-crop-production/

[3] Palampur, C.S. (2018) Effect of Micronutrient Application on Crop Productivity and Major Nutrients Use Efficiency, ppt. Department of Soil Science, College of Agriculture, Munish Sharma. (In Egypt)

https://www.slideshare.net/munishsharma0255/effect-of-micronutrient-application -on-crop-productivity-and-major-nutrients-use-efficiency?qid=5619b35f-90c0-46a9 -ab6d-43fb8fc59c12\&v=\&b=\&from_search $=1$

[4] Jacobs, L. (2008) Micronutrients Needed by Crops, PPT, MWEA Biosolids Conference, Bay City, Michigan, February 21, 2008, Department of Crop and Soil Sciences, Michigan State University. (In Egypt)

https://www.powershow.com/view/3c713f-YzEzY/Micronutrients_Needed_by_Cro ps_Lee_Jacobs_Department_of_Crop_and_Soil_Sciences_Michigan_State_Universi ty_powerpoint_ppt_presentation

[5] Horiba (2018) Soil pH and Nutrient Availability-Application Notes. (In Egypt) http://www.horiba.com/fileadmin/uploads/Scientific/water_quality/Documents/Ap plication_Notes/HIS/22_-_Soil_pH_and_Nutrient_Availability.pdf

[6] Nutrient Stewardship (2018) Soil pH and the Availability of Plant Nutrients. (In Egypt)

https://www.nutrientstewardship.com/implementation/soil-ph-and-the-availabilityof-plant-nutrients/

[7] White, J. (2018) Mapping Soil Micronutrients. Field Crops Research, 60, 11-26. (In Egypt) https://doi.org/10.1016/S0378-4290(98)00130-0 https://www.researchgate.net/publication/223493553_Mapping_soil_micronutrients

[8] Aich, V., More, N.B., Udayana, S.K. and Patil, G.D. (2017) GPS-GIS Based Soil Maps of Micronutrients Status in Organic Farms at College of Agriculture. Pune (M.S.), India.

[9] Egyptian Survey Authority, Damanhour City, El-Bouheria Governorate (1998) 1:50000 Scaled-Topographic Maps of El-Bouheria Governorate.

[10] ESRI (2009) Arc-GIS, USA. 
[11] Kettler, T.A., Doran, J.W. and Gilbert, T.L. (2001) Simplified Method for Soil Particle-Size. In: Determination to Accompany Soil-Quality Analyses, USDA-ARS/UNL Faculty U.S., 849-852.

[12] Page, A.L., Miller, R.H. and Keeny, R. (1982) Methods of Soil Analysis. Part 2. Chemical and Microbiological Properties, Agron. Monograph No. 9, ASA, Madison, WI, USA.

[13] Soltanpour, P.N. (1991) Determination of Nutrient Availability and Elemental Toxicity by AB-DTPA Soil Test ICPAES. Advances in Soil Science \#16, Springer-Verlag, New York.

[14] Rodriguez, J.B., Self J.R. and Soltanpour, P.N. (1994) Optimal Conditions for Phosphorus Analysis by the Ascorbic Acid-Molybdenum Blue Method. Soil Science Society of America Journal, 58, 866-870. https://doi.org/10.2136/sssaj1994.03615995005800030034x

[15] Calabi-Floody, M., Medina, J., Rumpel, C., Condron, L., Hernandez, M., Dumont, M. and Mora, M. (2017) Smart Fertilizers as a Strategy for Sustainable Agriculture. Advances in Agronomy, 147, 119-157. https://doi.org/10.1016/bs.agron.2017.10.003

[16] Abd El-Hady, A.M., Abdelaty, E.F. and Boder, A.E. (2017) Assessment of Heavy Metals Pollution of Some Water Resources (Kafr El-Dawar-Egypt). Natural Resources, 8, 306-319. https://doi.org/10.4236/nr.2017.84019

[17] FAO (1990) Guidelines for Soil Profile Description. 3rd Edition, FAO, Rome. 